Examining individual intention to share knowledge with people from other tribes

Eugene Okyere-Kwakye

Koforidua Technical University, Ghana

Khalil Md Nor

Universiti Teknologi Malaysia, Malaysia

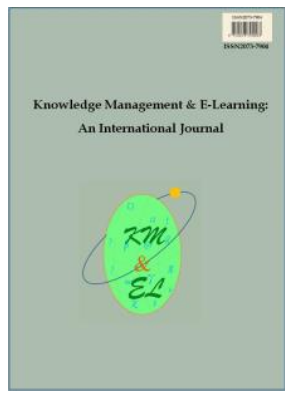

Knowledge Management \& E-Learning: An International Journal (KM\&EL) ISSN 2073-7904

Recommended citation:

Okyere-Kwakye, E., \& Nor, K. M. (2020). Examining individual intention to share knowledge with people from other tribes. Knowledge Management \& E-Learning, 12(3), 315-343. https://doi.org/10.34105/j.kmel.2020.12.017 


\title{
Examining individual intention to share knowledge with people from other tribes
}

\section{Eugene Okyere-Kwakye*}

Faculty of Business of Management Studies

Koforidua Technical University, Ghana

E-mail: eokyerekwakye2@gmail.com

\section{Khalil Md Nor $\mathbb{6}$}

Faculty of Management

Universiti Teknologi Malaysia, Malaysia

E-mail: kmdnor@management.utm.my

*Corresponding author

\begin{abstract}
While extensive studies have been conducted to understand the factors that influence individual intentions to share knowledge, a review of the literature shows that these studies did not consider the effect of the individual sentiment of the knowledge sharer in the act of sharing knowledge. Individuals coming from different tribes might have sentiments against each other, which could influence their communication and social interaction and thus affect knowledge sharing. This study collected data from lecturers in ten polytechnic institutions in Ghana using a questionnaire and analyzed the data using the structural equation modelling (SEM) technique. The findings show that attitude, subjective norm, equal status, cooperativeness, identification, top management, and immediate superior have a significant influence on individuals' intention to share knowledge with people from other tribes. Contrastingly, common goal, institutional support, and friendliness do not influence individuals' attitude to share knowledge with people from other tribes.
\end{abstract}

Keywords: Multitribalism; Knowledge sharing; Intention; Theory of reasoned action; Attitude; Subjective norm; Equal status; Friendliness

Biographical notes: Dr. Eugene Okyere-Kwakye completed his PhD education at the Universiti Teknologi Malaysia and he is a Senior Lecturer at the Koforidua Technical University, Ghana. His research interests include Knowledge Management, E-commerce, Cross-cultural training (tribes) and entrepreneurship.

Khalil Md Nor is a full Professor at the Universiti Teknologi Malaysia, Malaysia. He is a member of the Business Administration Department, Faculty of Management. He received his $\mathrm{PhD}$ in Management Information Systems from Southern Illinois University Carbondale, USA. His research interests include: Technology Acceptance, Knowledge Management, E-commerce, and Organisational Management. 


\section{Introduction}

Ghana is seen to be one of the countries in Africa that has rich cultures with almost about thirty-two ethnic-tribal lines. Diversity is considered to a strength for development but in the case of Ghana, it is seen as a detriment. The citizens in the country have been divided based on ethnic and tribal lines. It is believed that individuals who are polarized on ethnic grounds would also extend the polarization to their workplaces where knowledge, experiences and other ideas would be exchanged based on tribe and ethnic sentiments. To this regard, Ghanaian organisations could face challenges to foster knowledge sharing in the organisations if they are unable to address these ethnicity and tribalism issues. Therefore, it is crucial to identify, understand and reduce ethnic and tribal sentiments for employees to share knowledge with other employees regardless of their differences in /the tribal background.

Knowledge management has four important processes i.e., knowledge discovery, knowledge capture, knowledge sharing and knowledge application (Becerra-Fernandez et al., 2004; Nonaka \& Takeuchi, 1995). Essentially, knowledge sharing as discussed is one of the core blocks of knowledge management. Perhaps it is the most important aspect of knowledge management (Bock \& Kim, 2002). Knowledge sharing is defined as a deliberate act that makes knowledge reusable by other people through transfer (Lee \& AiHawamdeh, 2002). According to Hislop (2003), knowledge sharing is a process of exchanging ideas to create new knowledge. Van Den Hooff and de Ridder (2004) denote knowledge sharing as a give and take affair. From a business perspective, Tsui et al. (2006) defined knowledge sharing as a process of exchanging ideas, technical know-how and experience among employees, researchers, managers and other decision-makers in the organisation. This definition covers all the stakeholders of an organization. Knowledge sharing is the process through which one unit is affected by the other through knowledge (Argote et al., 2000). Ipe (2003) defined knowledge sharing as the action of releasing knowledge to others within the organization. According to Gupta and Govindarajan (2000), the act of identifying, transmission and the inflow of knowledge from one person to another person, group or an organisation is termed as knowledge sharing. Bartol and Srivistava (2002) further classified knowledge sharing as the exchange of insight, ideas, and experience between employees in an organisation to improve performance.

Knowledge sharing consists of procedures and techniques used to get the most from tacit and explicit knowledge in the organisation (Teece, 2003; Punniyamoorthy \& Asumptha, 2019; Rafique et al., 2017). The study of knowledge sharing, which is how an organization obtains access to its own and other organizations' knowledge, has emerged as a key research area from a broad and deep field of study on technology transfer and innovation, and more recently from the field of strategic management. Increasingly, knowledge-sharing research has moved to an organizational learning perspective (Li et al., 2016). Experience and research suggest that successful knowledge sharing involves extended learning processes rather than simple communication processes, as ideas related to development need to be made locally applicable with the adaptation being done by the incumbent firms (Nguyen, Dinh, \& Tuan, 2019; Probst et al., 2000; Zhang et al., 2016). According to Libowitz and Chen (2001), knowledge sharing is an edge to create knowledge, which increased employees' organizational development. More specifically, the intention to share knowledge can be defined as the degree to one's perception of his or her willingness to share knowledge (Bock et al., 2005). Individual intention to share knowledge measure the actual willingness of a person to engage in knowledge sharing with others in the future. This is akin to the main branch "knowledge sharing behaviour" 
of an individual. Therefore, this study would investigate individuals' intention to share knowledge in multi-tribal settings.

Developed countries have experienced tremendous change through knowledge of intensive investments. According to Noor and Salim (2011), the growth of a country's wealth depends on the effective acquisition, sharing and the application of knowledge to create value.

At the organizational level, companies would enjoy enormous benefits when employees are encouraged to share their knowledge. Cabrera and Cabrera (2002) in their study posited that knowledge sharing may provide a lot of benefits to the organization when the organizations decide to engage in it. According to Riege (2005), knowledge is the bedrock of every organization, thus an organization may fail if knowledge is not managed. In a study conducted by KPMG (2003) reports' that, about 80 per cent of firms in Europe utilize knowledge sharing as a competitive advantage. In support of this report, Holmstrom (2014) depicted that the degree to which a firm may be able to create quality goods and services faster than its competitors is normally based on the knowledge sharing culture in the organization. In another view, knowledge sharing was denoted as a strategy to provide a competitive advantage through organizational teams. This is the ability of the teams to perform productively through interactions among team members. Team members engaging in knowledge sharing practices can create a unique knowledge resource that would be difficult for competitors to imitate. Therefore, the sharing of knowledge among team members enhances organizational performance (Srivastava et al., 2006).

Scholars (e.g., Rosendaal, 2009) have expressed that ethnic diversity could be akin to a two-sided sword i.e., it provides advantages as much as disadvantages to organizations. On the aspect of the advantages, Bodenhausen (2009) argued that diverse ethnic group are better than the homogenous groups. Also, Bogenrieder and Noteboom (2004) consider ethnic diverse groups to be creative, interactive and provide low attrition rate that culminates to higher productivity than the homogenous groups. On the aspect of the disadvantages, Rosendaal (2009) posits that diverse groups may have a variant cognitive understanding, which could lead to difficulty in solving group problems, which can result in conflict. Scholars have argued that diverse group mostly suffer in decision making since members may have different views due to their different cultural background (Rosendaal, 2009; Bogenrieder \& Noteboom, 2004). Diversity may also affect employee interaction, hence knowledge sharing. Therefore, understanding the importance of cultural diversity, in particular ethnicity and tribalism in the context of knowledge sharing would be crucial to extend current knowledge on knowledge sharing intentions in organizations where employees differ in cultural background.

\section{Review of studies on knowledge sharing}

Based on the previous section, understanding the importance of ethnicity and tribalism in the context of knowledge sharing would help extend the current knowledge in the knowledge management research domain. To achieve this aim, we found it necessary to review all related studies examining knowledge sharing using the keyword "individual knowledge sharing" on the online databases search such as Scopus, Emerald, Springer, JSTOR and Science Direct from the year 2005-2015. The review shows that many studies have been conducted in the knowledge sharing field. However, in terms of the context, it has been found that most of the previous studies were mainly conducted in academic institutions where students, high school teachers, and university lectures were used as 
respondents. Other studies also focused on organisations where managers and employees in public organisations, private organisation, manufacturing organisation, healthcare industry and multinational companies were used as respondents. Some previous studies also focused on social media users where it users, Facebook user, computer users and Internet users were used as respondents (Keong \& Subhi, 2015; Mehrabani \& Mohammed, 2011; Aziri, Veseli, \& Ibraimi, 2013; Yahya \& Goh 2002; Chiu et al., 2006; Liu, 2008; Wasko \& Faraj, 2005; Lin, 2006; Hew \& Hara, 2007; Panahi et al., 2013; Adeyelure, Kalema, \& Motlanthe, 2019; Kim, Lee, \& Elias, 2015).

We observed that the respondents used in all these studies were homogenous in terms of their characteristics as they might have shared similar culture and national values. We feel that the prior researchers did not consider or emphasised on the elements in investigating knowledge sharing. Thus, the differences in culture, values, and other characteristics could make people feel reluctant to share knowledge. Murphy et al. (2013) suggests that it is more likely for people to share to their kind than other people. Boh et al. (2013) conducted a study to investigate the influence of culture alignment, trust, openness to diversity and national culture on knowledge sharing among people from different nationalities in an organization. They found that culture alignment, trust, national culture and openness to diversity influence knowledge sharing. In another study, Alkhaldi et al. (2011) attempt to explore the effect of power distance, collectivism, openness to diversity and individualism among people from different nationality. Their study was conducted among employee from a different race. They found collectivism, power distance, individualism, openness to diversity to influence knowledge sharing. Khatri et al. (2006), also examines the effect of individuals' national culture on knowledge sharing in an organization. The study concluded that national culture has a positive significant effect on individuals' knowledge behaviour. Lastly, Slump (2013) attempted to explore the influence of superiority and subordinate status of nationalities on knowledge sharing among employees in a multinational organisation. The study found that superiority and subordinate positions of diverse nationalities influence knowledge sharing in the organisation. Even though the studies discussed above focused on heterogeneous contexts yet, none of them considers investigating knowledge sharing in a multitribal context. They focused on different nationalities in multinational organisations which is different from the contexts of tribes where the individuals are similar in stature, sometimes colour and language yet they discriminate based on their tribes. However, the process of segregation among the tribe members may be similar to race and national culture formation. Thus, with race and national culture, people can easily differentiate themselves based on skin colour, nose shape and eyeball colour. This is termed as shallow diversity (Cox, 2001). For instance, it is easy to differentiate between European and Black African. However, when it comes to tribes, the people may have similar features, like skin colour, language and others but the tribe origin makes the difference.

Interestingly, classifying Ghana in the domain of diversity according to Cox (2001) can be denoted as deep diversity. The 32 ethno-lingua clans are very similar in nature when it comes to their colour, characteristics and appearance. The difference can only be noticed through the spoken language and name of an individual. Surprisingly, even though the people of Ghana share a similar identity there is still an existence of tribalism. People attempt to segregate based on their language and tribes. This connotes to the Faultline theory which premises that, individuals in a heterogeneous group split into relatively homogeneous subgroups based on the group members' (Lau \& Murnighan, 1998). In this case, people look for a shared identity for an alliance. The point of alignment can be a demographical factor such as age, gender and job tenure. Then one could deduce that tribal association could affect knowledge sharing. For instance, Ghana is made up of numerous tribes, ethnicity, clans and communities with numerous 
languages. Specifically, there are about six (6) main ethnic groups in Ghana, which consists of the Akan, the Ewe, the Ga-Adangbe, the Mole-Dagbani, the Guan, and the Gurma. These tribes are being represented in the nation as Akan 45.3\%, Mole-Dagbon $15.2 \%$, Ewe 11.7\%, Ga-Dangme 7.3\%, Guan 4\%, Gurma 3.6\%, Grusi 2.6\%, MandeBusanga $1 \%$, other tribes $1.4 \%$, other $7.8 \%$ (Ghana Statistical Service, 2000 census). There are about sixteen (16) main distinctive languages, which are spoken by each of these ethnic groups: a situation, which is noted as one of the major problems of the nation.

In Ghana, social institutions like marriage, schools, mosques, churches and political groups are currently arranged based on tribes and spoken languages. Besides, people marry based on their tribal background. In partisan politics, voting is based on the tribe and ethnicity of the party's flag bearer. Electorates vote for their tribesmen without considering any social or developmental issues. This segregation in language and other cultural fundamentals in Ghana became a thorn in the flesh of national development to the extent that the fourth Prime Minister of Ghana enacted a law that banned the use of "Tribe" on any official document. Following these events, one would agree with the researcher that, Ghana's 16main distinctive languages portend many problems as people forget about the national development agenda in favour of tribe and ethnicity.

\subsection{Individual factors, tribalism and knowledge sharing}

Looking at the level of tribalism exhibited by Ghanaian citizens, it is evident to warrant a conclusion that employees would extend this behaviour to their respective workplaces where people would feel reluctant to share their knowledge, experience and ideas to people from other tribes. Accentuating the existence of tribalism in Ghana, the researchers feel it is necessary to search for factors that could overcome the level of tribalism among the individuals. To achieve this, a literature review was conducted. The result of the literature review shows that the individual factors used in examining knowledge sharing can be categorised into four (4) i.e., personality factors, sociocognitive factors, demographic factors and motivational factors. Example of the personality factors used include agreeable, introvert, and extrovert (see Ardichvili et al., 2006; Abdul Manaf \& Mazulki, 2013). On socio-cognitive factors, most studies used the subjective norm, reciprocity, attitude, altruism, trust, competition, self-efficacy and reputation enhancement (Hamphil \& Likowitz, 2012; Tohidinia \& Mosakhani, 2010; Huang et al., 2008; Rahman et al., 2014; Kim et al., 2015; Tsai \& Cheng, 2012; Kankanhalli et al., 2005; Endres et al., 2007; Hassandoust et al., 2011; Lee et al., 2014; Ho et al., 2012; Bock et al., 2005).

Demographic factors used in examining knowledge sharing are age, gender, tenure and level of education (Boateng, Dzandu, \& Agyemang, 2015; Gumus, 2007). Lastly, motivational factors used in examining knowledge sharing include intrinsic and extrinsic reward, perceived enjoyment, perceived benefit and cost and recognition (Amin et al., 2011; Hau et al., 2013). Importantly, as these studies were conducted with homogenous respondents, we anticipate the possibility for these individual factors studied in previous research to exclude an adequate explanation on individuals' intention to share knowledge in a multi-tribal setting. Based on the review above the researcher found that the constructs used in the prior studies were not much grounded to a diversity theory. This is understandable because they were not investigating tribes. The constructs used explain how people share knowledge in homogenous contexts i.e., people from the same nationality, race etc. Hence, there is a greater possibility that these factors may not be able to influence individuals to share knowledge in a multi-tribal context. Therefore, we 
further reviewed theories in previous studies and found that the intergroup contact theory and social identification theory would be useful in deriving these factors.

The intergroup contact theory, which was propounded by Allport (1954) rests on the premise that interaction between people from diverse groups is important to the acknowledgement of similarities and gaining knowledge about other people. The theory posits that prejudice could be reduced when individuals are in a relationship (Allport, 1954). The intergroup contact theory proposed that equal status, common goal, cooperativeness and institutional support would facilitate prejudice reduction (Allport, 1954). Based on the tenet of the intergroup contact theory which proposes the four factors that could facilitate a reduction in prejudice, the researcher deemed it appropriate to select equal status, common goal, institutional support and cooperativeness for the study. In addition, due to the understanding of intergroup contact theory as to how to reduce prejudice, we find friendliness to be an appropriate construct to be used for this study.

Moreover, identification was also to be included in the study. Identification was adopted from the Social Identify Theory (SIT), which was propounded by Tajfel and Turner (1979). The theory predicts that intergroup behaviours are based on the individuals' perceived status in an intergroup environment (Tajfel \& Turner, 1979). Essentially, the theory argued that individuals are motivated by the status they get from affiliating themselves with a group. Tajfel and Turner (1979) believed that an individual would do anything to identify with the group or the organization. The theory posits that the individuals' purpose is overshadowed by the overall goals of the group, which reduces the sentiments he or she has for other people in the organization. Therefore, an individual's prejudice will reduce when he or she is identified with the organization or group. The act of the individual identifying him/herself with the organization would overshadow any existing prejudice, which could lead to the formation of a positive attitude to share knowledge.

\subsection{Theory of reasoned action}

Since knowledge sharing is a behaviour, there is a need to find a well-known and suitable theory that can explain behaviour. Based on the review of previous literature, the researcher found the Theory of Reasoned Action (TRA) to be very useful for this study. TRA has attitude and subjective norm as its main determinants (Ajzen \& Fishbein, 1980). Essentially, the TRA was adopted as the main underpinning theory for this study because of its predictive power to explain behaviours that are within the control of the individual (Bock et al., 2005; Kim \& Lee, 2005). Theory of Reasoned Action was developed in 1967 and was later expanded by Ajzen and Fishbein in 1980. Attitude and subjective norm are the main determinants of TRA (Ajzen \& Fishbein, 1980). Therefore, attitude and subjective norm arrr3re also included in the study. TRA postulates that individuals' intention to share knowledge could be influenced by the individual's perceived social pressure to engage in behaviour from a referent group (Ajzen \& Fishbein, 1980). Based on the review from previous studies, the study found the institution and superiors to be potential referent groups that could influence individuals' intentions to share knowledge in a multitribal setting (see Jolaee et al., 2014; Cabrera et al., 2006). Therefore, the subjective norm was decomposed with top management and immediate superiors. 


\section{Research framework}

As aforementioned, the Theory of Reasoned Action, Intergroup Contact Theory and the Social Identity Theory were used as a theoretical framework for the study. The Intergroup Contact Theory to supports four (4) constructs i.e., (equal status, cooperativeness, common goal and friendliness). The Social Identity Theory supports identification. Social Identity Theory argues that an individuals' commitment to an organization would increase when the person is affiliated with the organization. In the multitribal context, the theory suggests that an individual who is identified or affiliated with the organization may not have any prejudice against colleagues from other tribes. Thus, an individual's affiliation or identification with the organization would increase his/her commitment towards the organization, which would diminish any sentiments against people from other tribes. Therefore, Social Identity Theory was used as a supportive theory for the study.

Attitude and subjective norm were derived from the Theory of Reasoned Action while institutional support and superior influence were derived from previous studies. As the study aims to investigate human behaviour, the TRA, which discusses individuals' intention to undertake an action or a behaviour was used as the baseline theory for the study. Also, the TRA was adopted to be used in this study because many researchers have confirmed the suitability of TRA in explaining individuals' intention to share knowledge (e.g. Hassandoust et al., 2011; Lin, 2007; Bock \& Kim, 2002; Rehab \& Wahyni, 2013; Ibragimova et al., 2012; Mahmood et al., 2011). These confirmations led the researcher to choose TRA as the baseline theory for the current study.

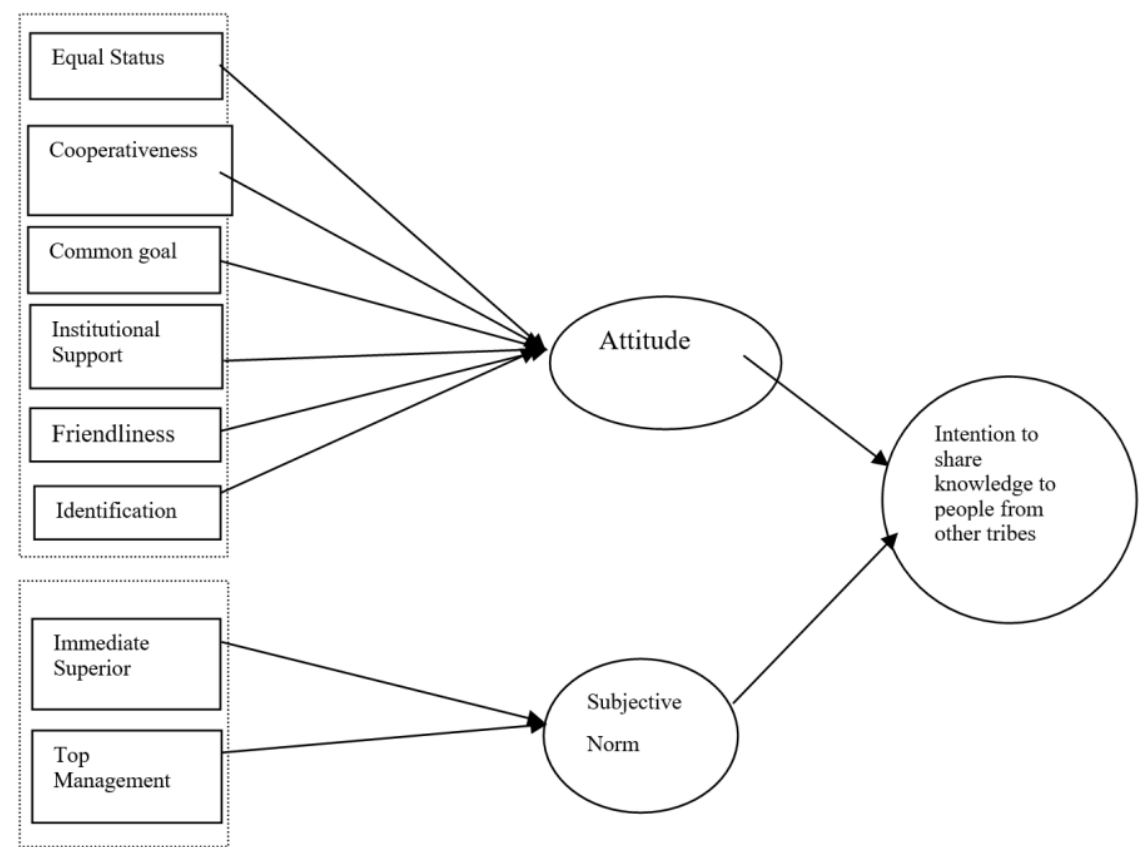

Fig. 1. Conceptual framework of the factors influencing knowledge sharing in a multitribal context

The research framework presented in Fig. 1 is formulated based on a review of previous studies, which highlight factors such as equal status, cooperativeness, common 
goal, and institutional support to be critical predictors of individual attitude to share knowledge. These variables were tested among lecturers in academic institutions. Ten hypotheses were developed and empirically tested. The next section presents a discussion that supports the development of the hypothesis in the research model.

\subsection{Equal status}

Equal status is difficult to conceptualize (Brown, 2005). Most researchers defined it based on the context in which it was used (Dovidio et al., 2001). In this study, equal status is defined as the degree to which individuals perceive they are of an equal social stand (Dovidio et al., 2001). In other words, equal status can be defined as the degree to which an individual believes that he or she has equal social status as the other person. According to Allport (1954), to enhance interactions, people from diverse background must engage equally in a working relationship. How equal status may influence attitude is easy to understand. People tend to form stereotype on other individuals' due to their inferiority complex or their inability to accomplish a certain task. When the person perceives him/herself as having a similar status as the other person, there is a likelihood that he/she may easily accept the other person from a different group without prejudice. Hence, the belief that the other person is of similar status as him or herself will lead to a positive attitude towards the other person. The positive or negative outcome of the evaluation is the "attitude" which pre-empts the behaviour (Ajzen, 1991). The equal status may reduce prejudice, which may lead to a positive attitude to perform a behaviour. In an experimental study conducted by Krahe and Altwasser (2006) to investigate the change in students' attitude towards other students with a handicap has found that, equal status influences students' attitude towards people with no handicap. In a recent study, Okyere-Kwakye et al. (2019) found that equal status has a positive significant influence on individuals' knowledge sharing behaviour in a multitribal context. It is to this backdrop that we feel that equal status influences individuals' attitude to share knowledge with people from other tribes. This leads to the next hypothesis:

Hypothesis 1: Equal status has a positive significant influence on individuals' attitude to share knowledge with people from other tribes

\subsection{Cooperativeness}

In this study, cooperativeness is defined as the degree to which a person attempts to satisfy the other person's interest or concern without competition (Wilmot \& Hocket, 2001). Looking at it from the organizational perspective, cooperativeness can be denoted as a personality trait that determines the predisposition of individuals' commitment towards an organisation (Lin, 2007). Cooperativeness is a personality trait where an individual is supportive and agreeable with other people (Yilmaz \& Hunt, 2001). The individual will work with other people without sentiment or competition. According to Allport (1954), cooperativeness is a variable that could reduce prejudice among people from diverse groups. A cooperative person is always willing and eager to work with other people notwithstanding their origin. Cooperativeness overrides any sentiments or prejudices that he/she has for the other person. The cooperative personality leads to a positive attitude to engage in a certain behaviour with other people. Thus, in the context of this study, cooperativeness will influence an individual's attitude to share knowledge. The favourable or the unfavourable outcome of the evaluation is the "attitude" which initiates the behaviour (Ajzen, 1991). For instance, in a study conducted by Feuchte (2010) to examine the influence of cooperativeness among refugees from Liberia who were based in Ghana, it has been found that some of the refugees were helping others on 
the food aid program despite the differences in their tribal or ethnic backgrounds. Cooperativeness could be affecting their attitude towards other people. Based on this backdrop, the researcher believes that cooperativeness will influence individuals' attitude to share knowledge with people from other tribes. This leads to the next hypothesis:

Hypothesis 2: Cooperativeness has a positive influence on individuals' attitude to share knowledge with people from other tribes

\subsection{Common goal}

In the context of this study, a common goal is defined as the degree to which individuals shared similar/common desirable goals in the organization. According to Allport (1954), a common goal leads to a situation where two or more people work towards a shared goal. When individuals perceive themselves as having a common goal, they attempt to achieve it without considering any prejudice. They tend to focus on the attainment of the shared objective than any other thing. The edge to accomplish the common goal tends to supersede the prejudice for the other persons (Dovidio et al., 2001). Therefore, the common goal reduces prejudice, which leads to a positive attitude towards the other person. For instance, footballers in the English Premier league who are of diverse nationalities turn to interact and play as a team because they share a common goal of winning the game. At the time of playing, these players have to rely on and connect with the other team members from different positions to win the game without any prejudice. In the context of knowledge sharing, an individual will share his or her knowledge when there is the pursuit of a common goal. The common goal will reduce any prejudice, which influences his or her attitude to share knowledge. This means that the common goal supersedes the personal goals of the individual. The shared goal /common becomes the focal point, which limits the individuals from stereotyping others. Allport (1954) suggests that employees should be given a common task to avoid prejudice. Providing employees from different tribes with a common goal would reduce prejudice that leads to a positive attitude in behaviour. Based on these discussions, we postulate that a common goal may influence individuals' attitude to share knowledge with people from other tribes. Hence, the next hypothesis is stated:

Hypothesis 3: Common goal has a positive significant influence on individuals' attitude to share knowledge with people from other tribes

\subsection{Friendliness}

In this study, friendliness is defined as the degree to which an individual enjoys a relationship with other people in the organization. According to Allport (1954), friendship may develop from constant interaction and self-expansion, which would proceed to reduce prejudice. Logically, a friendship develops intimacy between two people. The intimacy creates a bond that holds them together as they attempt to support and show kindness to each other. Because of shared intimacy, it becomes very difficult to stereotype against each other (Brown, 2005). In addition, the friendship reduces the prejudice, which leads to a positive attitude towards the other person (Pettigrew, 1973). The relationship between friendliness and knowledge sharing has not been given much attention. Most studies have examined the input-friendliness of technological devices on knowledge sharing (Hall, 2001; Brown \& Duguid, 2000) without considering the influence of friendly relationship among individuals and knowledge sharing. As aforementioned, friendliness would develop a bond between two people which would limit prejudice; hence, influence their attitude towards each other. Therefore, we 
postulate that friendliness would influence an individual's attitude to share knowledge with people from other tribes.

Hypothesis 4: Friendliness has a positive significant influence on individuals' attitude to share knowledge with people from other tribes

\subsection{Institutional support}

Institutional support can be defined as the degree to which an institution provides the necessary logistics and rules to support behaviour. In the context of knowledge sharing, institutional support can be defined as the degree to which an individual believes the institution expects him/her to share knowledge. The provision of institutional support logically would propel the individual to engage in knowledge sharing behaviour. Institutional support is considered as one of the important issues in management studies. Accordingly, employees would be motivated to share their knowledge when the institution provides the necessary logistics to support knowledge sharing activities. Cabrera et al. (2006) posit that the quality of knowledge sharing will be improved if institutions attempt to invest in it. In the context of this study, one can infer that employees would be motivated to share knowledge with people from other tribes when they perceive support from the organization. Sentiments and prejudice would be reduced when the management of the organization sanctions the knowledge sharing activity. A study conducted by Igbaria et al. (1996) found organizational support to have a positive significant influence on the subjective norm. Similarly, a current study conducted by Jolaee et al. (2014) found institutional support to have a positive significant relationship with the subjective norm. Therefore, we proposed that institutional support might influence individuals to share knowledge from other tribes. Therefore, the next hypothesis is stated:

Hypothesis 5: Institutional support has a positive significant effect on the subjective norm to share knowledge with people from other tribes

\subsection{Identification}

In this study, identification is the degree to which an individual sees him/herself as one with another person or group of people. Identification is defined as "one's conception of self in terms of the defining features of the self-inclusive social category" (Chiu et al., 2006). This means that identification is about how an employee sees him/herself to be part of the organization community. Generally, an individual will attempt to identify him/herself with his or her organization, especially when the organization is prestigious as it improves his/her status. Attempting to be accepted by the organizational members, the individual tends to be committed by making the organizational vision dominate his or her personal goals (Nahapiet \& Ghoshal, 1998). This metamorphosis will make the person identify with the organization. To be part of the organization, the individual needs to accept the norms and goals of the community.

Thus, the individual feeling as part of the organizational community will reduce any stereotype that he or she has for other people in the group or community. Therefore, the act of the individual identifying him or herself with the organization will reduce prejudice and lead to a positive attitude towards the other people. The effect of identification on attitude has been theorized and validated in few empirical studies (Hassandoust et al., 2011; Hwang \& Kim, 2007). For example, in their recent study, Hassandoust et al. (2011) found identification to influence individuals' attitude to share 
knowledge. In another study, Hwang and Kim (2007) found that identification was positively related to the attitude of students toward using the group email function in an online classroom management system to share knowledge. The above previous studies were conducted in homogeneous settings. We feel that identification will still influence individuals' attitude to share knowledge in heterogeneous contexts i.e., multitribal settings. The feeling of community will overcome their prejudice and would lead to a positive attitude. Therefore, the next hypothesis is stated:

Hypothesis 6: Identification has a positive significant influence on individuals' attitude to share knowledge with people from other tribes

\subsection{Decomposing subjective norm}

The subjective norm in this study refers to the individuals' perception of social pressure to engage or not to engage in knowledge sharing. People will be more inclined to engage in a certain behaviour if they feel that important referent individuals expect them to engage in it. Prior studies have identified several referent groups that exert social pressure on individuals to perform behaviour. Cabrera et al. (2006) found superior and peers to influence knowledge sharing. According to a study on computer and technology usage, Taylor and Todd (1995) found peers and superiors to influence individuals' intention to use a computer. In another study, Karahanna et al. (2005) found that the MIS department, computer experts, friends, peers, supervisor and top management influence individuals' intention to use IT. In a study on the influence of the organization, Jolaee et al. (2014) and Nesheim and Smith (2015) found the institution as an influence on individual's knowledge sharing. Lastly, top management support was also found to influence individuals' knowledge sharing behaviour (Tan \& Zhao, 2003; Lin, 2007). Based on the results of the above studies, we feel that these two referent groups i.e., (top management and immediate superior) may influence the individual's perceived social pressure on whether to share or not to share knowledge in a multitribal setting. This leads to the eighth and ninth hypotheses:

Hypothesis 7: Immediate supervisor has a positive significant effect on the subjective norm to share knowledge with people from other tribes

Hypothesis 8: Top management has a positive significant effect on the subjective norm towards individuals' intention to share knowledge with people from other tribes

\subsection{Attitude}

The line of studies examining attitude is mostly grounded in the theory of reasoned action and the theory of acceptance model, which postulate that the individual's behaviour is mainly influenced by his or her attitude and beliefs (Ajzen \& Fishbein, 1980; Davis, 1989). According to Venkatesh and Brown (2001), attitude is about favourable or unfavourable feelings that individuals have on behaviour. It can also be defined as a person's positive or negative feelings toward a behaviour (Ajzen, 1991). Intention to engage in a behaviour will take place if the person has a positive evaluation about the behaviour and vice versa when he/she considers the result of the intended behaviour to be negative (Ajzen, 1991). Therefore, a favourable attitude would promote a strong intention to engage in the behaviour. In the context of this study, attitude to sharing knowledge can be denoted as the degree of a person's favourable or unfavourable feelings about knowledge sharing. A positive evaluation indicates that an individual believes that the knowledge shared would not cause any harm or the individual may derive benefits from 
the knowledge sharing activity. Thus, this leads them to share knowledge. We feel that an individuals' intention to share knowledge to people from other tribes may also be influenced by his/her attitude on knowledge sharing. Strong attitude may overcome the tribalism sentiment and lead to the individual to share knowledge with people from other tribes.

Thus, the next hypothesis is stated:

Hypothesis 9: Attitude to share knowledge has a positive significant relationship with an individuals' intention to share knowledge with people from other tribes

\subsection{Subjective norm}

According to Ajzen (1991), the subjective norm can be denoted as the perceived social pressure to engage in a certain behaviour. Accordingly, subjective norms are formed from normative beliefs and the expectation belief from other relevant people for him or her to engage in a particular behaviour. In the context of this study, the subjective norm is defined as the degree of a persons' perceived social pressure to engage in knowledge sharing. The theory of social influence posits that an individual's choice to engage in a certain behaviour can be influenced by the people around him or her (Fulk et al., 1990). This means that people may consider the opinion of others before they engage in a certain behaviour. In the context of knowledge sharing, a person may share his or her knowledge when people who are important to him/her expect or feel that he/she should share. For instance, an employee would share knowledge when the manager is also sharing knowledge. The person might share knowledge because of the influence of the manager. We feel that the effect of subjective norm on individuals' intention will be similar in multitribal settings out of the respect they have for the people in the referent group. Therefore, this study suggests that an individual's intention to share knowledge with people from other tribes may be influenced by the expectation and the social pressure from people they deem important. Therefore, the second hypothesis is stated:

Hypothesis 10: Subjective norm to share knowledge has a positive significant influence on individuals' intention to share knowledge with people from other tribes

\section{Method}

\subsection{Instrumentation}

A questionnaire was used to collect data from the respondents. The questionnaire is made up of two parts i.e., section A and section B. The section A seeks for information on the respondents' characteristics such as age, education, gender, status, tenure, and their tribes. Section B consists of 49 Likert scale items that assess the constructs of the study. Five items were used to measure intention to share knowledge with people from other tribes, attitude to share knowledge, subjective norm, equal status, institutional support, friendliness, while four items were used to measure top management, immediate superior, cooperativeness and a common goal. The items used to measure the constructs in this study were predominately adopted and modified from previously validated instruments. These items were adopted and modified from (Lee, 2001; Lin, 2007; Taylor \& Todd, 1995; Chiu et al., 2006; Yilmaz \& Hunt, 2001; Bock et al., 2005; Lin, 2006; Goldberg et al., 2006; Spears et al., 1997). The details are provided in Appendix I. 
In this study, the dependent variable i.e., intention to share knowledge with people from other tribes was defined as the extent to which one intends to exchange and communicate experience, information and knowledge with people from other tribes. Attitude of sharing knowledge was operationalized as the favourable or unfavourable feelings that individuals have on knowledge sharing with people from other tribes. Subjective norm is defined as the degree of social pressure on an individual to share knowledge with people from other tribes. Equal status is the degree to which individuals perceive they have an equal social stand. Cooperativeness was operationalized as the extent at which a person attempts to satisfy other persons' interest or concern without competition. A common goal was operationalized as the degree to which individuals shared similar/common desirable goals in the organization. Institutional support is the degree of support that an institution provides to support knowledge sharing activities. Identification refers to the degree to which an individual attached or identify him/herself with the organization. Top management is the degree to which an individual believes that the top management expects him/her to share knowledge. Finally, immediate superior can be defined as the degree to which an individual believes that immediate superiors expect him or her to share knowledge.

\subsection{Respondents}

The questionnaire was distributed to 317 lecturers in ten polytechnics in Ghana, and a $100 \%$ return rate was achieved. The lecturers were chosen to be the respondents of this study because of the task they execute as knowledge-intensive workers who share knowledge with their colleagues for a successful job done. In addition, it is believed that the polytechnic lecturers are from diverse tribes, which forms the premise of the study. The polytechnics were located in the ten regions of Ghana and it is believed that each region represents a particular tribe. After screening the received data, 24 respondents were found to be outliers and were excluded for further analysis. Therefore, the data from the remaining 293 respondents were used for further analysis. The respondents were aged between 30 and 39 years. As depicted in Table 1, the educational background of the respondent consists of $21.8 \%$ with a bachelor's degree, $65.9 \%$ with a Master's Degree, and $12.3 \%$ with a PhD's degree. Concerning their rank, $19.5 \%$ were instructors, $23.9 \%$ senior instructors, $46.1 \%$ lecturers, $10.2 \%$ senior lecturers and 3\% Associate Professors. Finally, concerning the length of service, about $23.8 \%$ had served $1-2$ years, $36.2 \% 2-3$ years, 20\% 4-6 years, and 20\% 7 years and above. A total of $16.4 \%$ fall within the categories of 6-8 years of work experience and $12.6 \%$ had worked for 9 years and above. Finally, concerning the tribes of the respondents, a majority $(38.9 \%)$ of them are Akan's, with only $5.1 \%$ being Hausa, $11.3 \%$ being Guans, and $8.5 \%$ from other tribes/ethnicities. The distribution of tribes in this study more or less represents the actual situation in Ghana.

\section{Result}

\subsection{Measurement model}

In this study, the structural equation modelling (SEM) approach using SmartPLS statistical software (Ringle et al., 2005) was employed to test the hypotheses. Before the final analysis was conducted, the data collected were subjected to convergent and discriminant validity analysis. Factor loadings, composite reliability and average variance extracted were examined to assess the convergence validity. The convergent validity was 
performed to evaluate the degree of relatedness to the items measuring the same concept (see Table 2). The loadings for all items exceeded the recommended value of 0.6 (Chin, Gopal, \& Salisbury, 1997). Composite reliability values, which showed the degree to which the items indicated the latent construct, exceeded the recommended value of 0.7 (Hair et al., 2014). The average variance extracted (AVE) is in the range of 0.507 and 0.684 , which is also exceeded the recommended value of 0.5 (Hair et al., 2014). Next, the discriminant validity was conducted to confirm that the constructs are not correlated. Discriminant validity is a measure to determine that a construct does not reflect another construct within the same framework, and it is determined through the calculation of the square root of average variance extract (Fornell \& Larcker, 1981). The square root of AVE results indicated low correlations among the constructs (see Table 3). Thus, the overall measurement model demonstrated adequate convergent and discriminant validity.

Table 1

Demographic profiles $(\mathrm{N}=293)$

\begin{tabular}{|c|c|c|c|}
\hline Variables & Category & Frequency & Percentage (\%) \\
\hline \multirow[t]{2}{*}{ Gender } & Male & 184 & 62.8 \\
\hline & Female & 109 & 37.2 \\
\hline \multirow[t]{4}{*}{ Age } & $20-29$ & 73 & 24.9 \\
\hline & $30-39$ & 136 & 46.4 \\
\hline & $40-49$ & 58 & 19.8 \\
\hline & $50-59$ & 26 & 8.9 \\
\hline \multirow[t]{3}{*}{ Education } & Bachelors & 64 & 21.8 \\
\hline & Masters & 193 & 65.9 \\
\hline & $\mathrm{PhD}$ & 36 & 12.3 \\
\hline \multirow[t]{5}{*}{ Rank } & Instructor & 57 & 19.5 \\
\hline & Senior Instructor & 70 & 23.9 \\
\hline & Lecturer & 135 & 46.1 \\
\hline & Senior Lecturer & 30 & 10.2 \\
\hline & Assoc. Prof & 1 & 03.0 \\
\hline \multirow[t]{4}{*}{ Tenure } & $0-2$ & 89 & 30.4 \\
\hline & $3-5$ & 119 & 40.6 \\
\hline & $6-8$ & 48 & 16.4 \\
\hline & 9 yrs. and Above & 37 & 12.6 \\
\hline \multirow[t]{6}{*}{ Tribe } & Akan & 114 & 38.9 \\
\hline & Ga-Adangbe & 45 & 15.4 \\
\hline & Ewe & 61 & 20.8 \\
\hline & Hausa & 15 & 5.1 \\
\hline & Guan & 33 & 11.3 \\
\hline & Other Ethnic & 25 & 8.5 \\
\hline
\end{tabular}


Table 2

Factor loadings and reliability

\begin{tabular}{|c|c|c|c|c|c|c|c|c|c|c|c|}
\hline Items & AT & CG & $\mathrm{CO}$ & ES & FR & 1D & IS & SI & SN & $\mathbf{T P}$ & IK \\
\hline AT1 & 0.8572 & & & & & & & & & & \\
\hline AT2 & 0.8781 & & & & & & & & & & \\
\hline AT3 & 0.8917 & & & & & & & & & & \\
\hline AT4 & 0.8667 & & & & & & & & & & \\
\hline AT5 & 0.7965 & & & & & & & & & & \\
\hline CG1 & & 0.7343 & & & & & & & & & \\
\hline CG2 & & 0.8169 & & & & & & & & & \\
\hline CG3 & & 0.7216 & & & & & & & & & \\
\hline CG4 & & 0.7406 & & & & & & & & & \\
\hline $\mathrm{CO} 1$ & & & 0.832 & & & & & & & & \\
\hline $\mathrm{CO} 2$ & & & 0.6922 & & & & & & & & \\
\hline $\mathrm{CO} 3$ & & & 0.8134 & & & & & & & & \\
\hline $\mathrm{CO} 4$ & & & 0.6926 & & & & & & & & \\
\hline ES1 & & & & 0.8728 & & & & & & & \\
\hline ES2 & & & & 0.8411 & & & & & & & \\
\hline ES3 & & & & 0.8626 & & & & & & & \\
\hline ES4 & & & & 0.8586 & & & & & & & \\
\hline ES5 & & & & 0.8624 & & & & & & & \\
\hline FR1 & & & & & 0.698 & & & & & & \\
\hline FR2 & & & & & 0.778 & & & & & & \\
\hline FR3 & & & & & 0.787 & & & & & & \\
\hline FR4 & & & & & 0.767 & & & & & & \\
\hline FR5 & & & & & 0.738 & & & & & & \\
\hline ID1 & & & & & & 0.795 & & & & & \\
\hline ID2 & & & & & & 0.801 & & & & & \\
\hline ID3 & & & & & & 0.882 & & & & & \\
\hline ID4 & & & & & & 0.817 & & & & & \\
\hline IS1 & & & & & & & 0.743 & & & & \\
\hline IS2 & & & & & & & 0.749 & & & & \\
\hline IS3 & & & & & & & 0.724 & & & & \\
\hline IS4 & & & & & & & 0.854 & & & & \\
\hline SI1 & & & & & & & & 0.725 & & & \\
\hline SI2 & & & & & & & & 0.802 & & & \\
\hline S13 & & & & & & & & 0.743 & & & \\
\hline SI4 & & & & & & & & 0.793 & & & \\
\hline SI5 & & & & & & & & 0.749 & & & \\
\hline SN1 & & & & & & & & & 0.809 & & \\
\hline SN2 & & & & & & & & & 0.878 & & \\
\hline SN3 & & & & & & & & & 0.896 & & \\
\hline SN4 & & & & & & & & & 0.795 & & \\
\hline TM1 & & & & & & & & & & 0.759 & \\
\hline TM2 & & & & & & & & & & 0.850 & \\
\hline TM3 & & & & & & & & & & 0.834 & \\
\hline TM4 & & & & & & & & & & 0.782 & \\
\hline IK1 & & & & & & & & & & & 0.853 \\
\hline IK2 & & & & & & & & & & & 0.856 \\
\hline IK3 & & & & & & & & & & & 0.794 \\
\hline IK4 & & & & & & & & & & & 0.905 \\
\hline IK5 & & & & & & & & & & & 0.863 \\
\hline
\end{tabular}


Table 3

Inter-construct correlation

\begin{tabular}{|c|c|c|c|c|c|c|c|c|c|c|c|}
\hline Construct & AT & CG & $\mathrm{CO}$ & $\mathbf{E S}$ & FR & ID & IS & SI & SN & TM & IK \\
\hline Attitude & 0.868 & & & & & & & & & & \\
\hline Common goal & 0.331 & 0.763 & & & & & & & & & \\
\hline Cooperativeness & 0.456 & 0.452 & 0.756 & & & & & & & & \\
\hline Equal status & 0.229 & 0.261 & 0.234 & 0.861 & & & & & & & \\
\hline Friendliness & 0.332 & 0.256 & 0.385 & 0.198 & 0.757 & & & & & & \\
\hline Identification & 0.381 & 0.386 & 0.424 & 0.039 & 0.483 & 0.835 & & & & & \\
\hline $\begin{array}{l}\text { Institutional } \\
\text { support }\end{array}$ & 0.199 & 0.154 & 0.156 & 0.171 & 0.314 & 0.207 & 0.769 & & & & \\
\hline $\begin{array}{l}\text { Immediate } \\
\text { Supervisor }\end{array}$ & 0.27 & 0.198 & 0.146 & 0.033 & 0.151 & 0.345 & 0.271 & 0.777 & & & \\
\hline Subjective norm & 0.298 & 0.148 & 0.146 & 0.192 & 0.231 & 0.245 & 0.383 & 0.213 & 0.845 & & \\
\hline $\begin{array}{l}\text { Top } \\
\text { Management }\end{array}$ & 0.329 & 0.212 & 0.335 & 0.120 & 0.191 & 0.255 & 0.566 & 0.262 & 0.438 & 0.805 & \\
\hline $\begin{array}{l}\text { Knowledge } \\
\text { Sharing } \\
\text { Intention }\end{array}$ & 0.514 & 0.356 & 0.411 & 0.225 & 0.315 & 0.185 & 0.213 & 0.000 & 0.352 & 0.272 & 0.858 \\
\hline
\end{tabular}

Note. Diagonal elements are the square root of the AVE score

\subsection{Structural model}

A structural model describes the relationships between the independent and the dependent variables in the hypothesized model (Hair et al., 2014). The objective of the structural model as posited above is to examine the hypothesized relationships between the constructs. As mentioned in the previous section, the structural model was examined using the bootstrapping method in PLS. Fig. 2 shows the final research model containing the path coefficients and $R 2$. It also shows the significant effect of the independent variables on the intention to share knowledge to people from other tribes. From the result, R2 value for the intention to share knowledge is 0.299 , which shows that the two variables, that is attitude and subjective norm explain $29.9 \%$ of individuals' intention to share knowledge to people from other tribes.

Out of the ten hypotheses, the results supported seven hypothesized paths. The PLS results of the structural model showing the path coefficients and the t-statistics are depicted in Table 4. The results show that attitude towards knowledge sharing to people from other tribes $(\beta=0.44$ and $t$-value $=6.89, p<0.05)$, and subjective norm to share knowledge to people from other tribes $(\beta=0.21, t$-value $=3.58$, and $p<0.01)$ have significant relationships with the intention to share knowledge to people from other tribes. In addition, the results show that equal status $(\beta=0.12$ and $t$-value $=2.25, p<$ $0.01)$, cooperativeness $(\beta=0.28, t$-value $=3.61$, and $p<0.01)$, and identification $(\beta=$ 0.19 and $t$-value $=2.53, p<0.01)$ have a significant relationship with attitude to share knowledge. Furthermore, the results show that, top management $(\beta=0.33$ and $t$-value $=$ 4.91, $p<0.01)$, and immediate superior $(\beta=0.20, t$-value $=2.71$, and $p<0.01)$ have significant relationships with subjective norm to share knowledge to people from other tribes. However, three constructs were found not to have a significant influence on attitude to share knowledge to people from other tribes. The hypothesized paths that were not supported include the relationship between common goal, institutional support, 
friendliness and attitude towards intention to share knowledge to people from other tribes. Results of the relationships are depicted in Fig. 2.

Table 4

Summary of the structural model

\begin{tabular}{llrrrr}
\hline \multirow{2}{*}{ Hypothesis } & \multicolumn{1}{c}{ Relationship } & Path & Standard & T value & Results \\
& & Coefficient & Error & & Supported \\
H1 & Attitude $\rightarrow$ Knowledge sharing intention & 0.447 & 0.0653 & 6.658 & Supported \\
H2 & Subjective Norm $\rightarrow$ Knowledge sharing intention & 0.209 & 0.0582 & 3.602 & Supported \\
H3 & Equal Status $\rightarrow$ Attitude & 0.109 & 0.0557 & 1.962 & Sup \\
H4 & Cooperativeness $\rightarrow$ Attitude & 0.279 & 0.0733 & 3.808 & Supported \\
H5 & Common goal $\rightarrow$ Attitude & 0.089 & 0.0721 & 1.245 & Not supported \\
H6 & Institutional support $\rightarrow$ Attitude & 0.032 & 0.0585 & 0.561 & Not supported \\
H7 & Friendliness $\rightarrow$ Attitude & 0.053 & 0.0680 & 0.784 & Not supported \\
H8 & Identification $\rightarrow$ Attitude & 0.189 & 0.0799 & 2.360 & Supported \\
H9 & Immediate Superior $\rightarrow$ Subjective norm & 0.135 & 0.0721 & 1.882 & Supported \\
H10 & Top Management $\rightarrow$ Subjective norm & 0.380 & 0.0635 & 5.994 & Supported \\
\hline
\end{tabular}

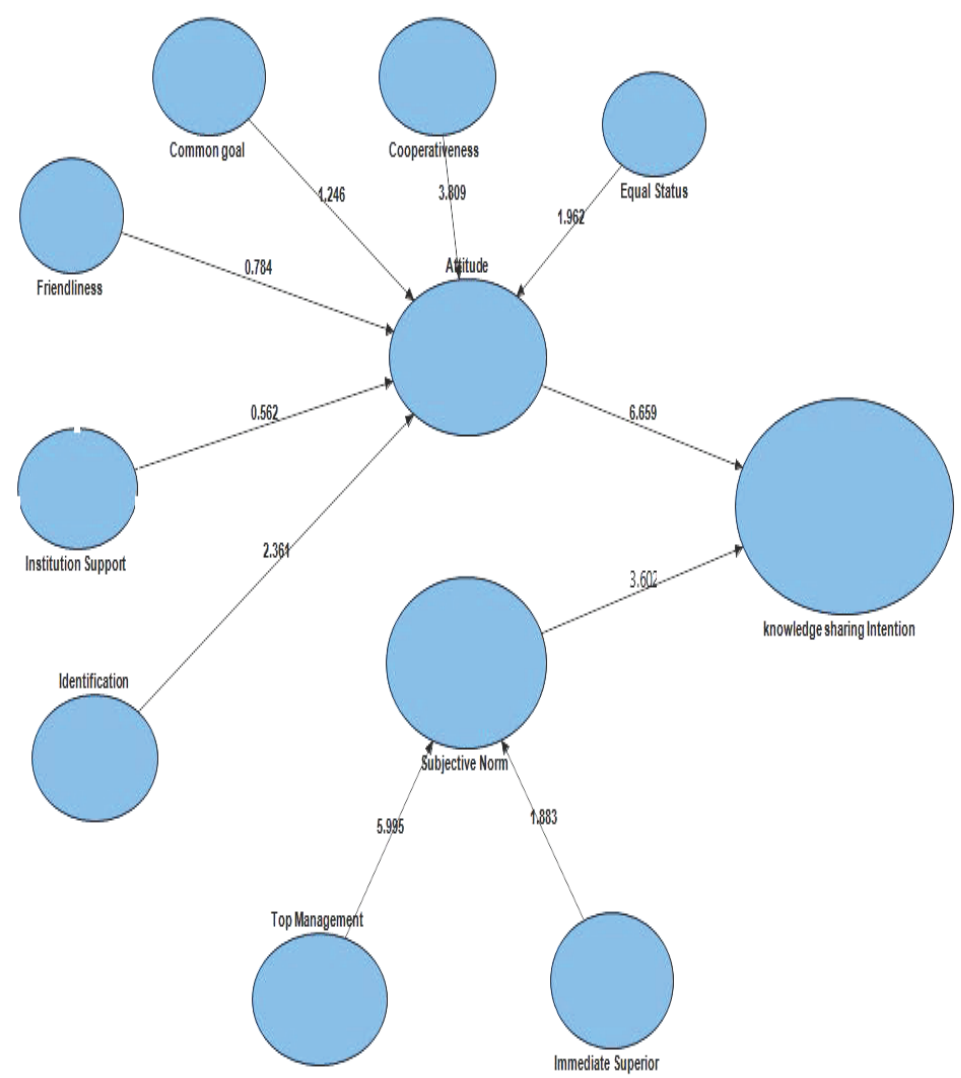

Fig. 2. The Structural model 


\section{Discussion and implications}

This study develops a model to examine the degree to which cooperativeness, equal status, common goal, institutional support, and friendliness and identification influence attitude to share knowledge in a multitribal setting. The influence of top management and immediate superior on the subjective norm was also determined. In addition, the study examines the relationship between attitude and subjective norm's influence on individuals' intention to share knowledge in a multitribal context. The findings of the study reveal that equal status, cooperativeness and identification have a positive significant influence on individuals' attitude to share knowledge with people from other tribes. However, the results show that common goal, institutional support and friendliness do not have an influence on attitude to share knowledge with people from other tribes. It is quite surprising that these factors do not have an influence on individual attitudes to share knowledge with people from other tribes. A common goal not influencing individuals' intention to share knowledge could be that, even though the respondents may share the mission, vision and goals of the organization, the employees' individual goals are not tied to the entire organizational goal. The success of the lecturers' job is very individual driven. The individual lecturer has a fundamental goal to set questions, mark scripts, teach and grade students, which is the main mission of the school, yet per the structures of the school these duties are seen as an obligation but not a contribution to the organizational vision. This means that even though the lecturer's work is important, they do not realize the importance of their contribution to the shared organizational goal. Therefore, the feeling of having a common goal with others is non-existent as they feel the impact of their contribution.

It is out of our expectation that institutional support was not found to influence individuals' intention to share knowledge with people from another tribe. As the support of an organization towards knowledge-sharing culture should motivate individuals to share knowledge. This negative result could be related to most employees to view their knowledge as an asset that belongs to the organization (Jarvenpaa \& Staples, 2001). As lecturers, they may perceive their knowledge as the reason for their employment. They see knowledge sharing as an obligation towards the organization. Therefore, organizational support would not influence their attitude to share knowledge. This is because they see knowledge sharing as an obligation or part of their job description but not as a reciprocate obligation from the organization supporting the knowledge sharing gesture. This implies that institutional support would not influence the lecturer's attitude to share knowledge with people from other tribes. Friendliness was also found to have no relationship with an individual's attitude to share knowledge with people from other tribes. However, the result of the study was contrary to the proposition of Allport (1954). The result indicates that friendliness does not have a significant influence on individuals' attitude. This is surprising because friendliness was expected to influence ones' attitude towards another person. The reason for the insignificant results could be related to the fact that knowledge sharing is seen as part of academic work. One does not have to be friendly before he/she would engage in knowledge sharing. For instance, a friendly or unfriendly lecturer will not hesitate to share his/her knowledge when a colleague asks for assistance to publish an article or help on how to use the college management system. The help being sought would be offered automatically since the receiver is a lecturer. Friendliness could influence an individual's attitude to share knowledge in general as claimed by Allport (1954) yet when it comes to specific behaviour such as knowledge sharing, it does not hold. Because the lecturers recognize knowledge sharing as part of their regular assignment, the friendly personality may not influence their attitude to share knowledge with colleagues. 
Adopting the Theory of Reasoned Action (TRA), the relationship between attitude and subjective norm and individuals' intention to share knowledge with people from other tribes were verified. Fortunately, the result shows that both attitude and subjective norm have positive significant influence on an individual's intention to share knowledge with people from other tribes. This result is in consonance with the findings of several other studies that found attitude and subjective norm to have a positive relationship with knowledge sharing even though these studies were not conducted in multitribal contexts, thus the result would hold. These results imply that attitude and subjective norm are not only important factors to predict knowledge sharing among individuals from a heterogeneous context but also individuals in a heterogeneous context, specifically in a multitribal setting. As mentioned in the previous section, the subjective norm was divided into top management and immediate superiors. The relationship between these two factors and subjective norm to share knowledge with people from other tribes were examined. The results show that both top managers and immediate superiors have an influence on the individual's subjective norm to share knowledge with people from other tribes. This implies that employees would be influenced to share their knowledge with people from other tribes when they perceive their top management and immediate supervisors engaging in it.

\subsection{Managerial implication}

The results provide varied implications for academic and other organizational managers. The result of the study found attitude to influence knowledge sharing. This suggests that management should attempt to reward, empower and engage employees in decision making which would create a positive attitude among employees. Also, the result of the decomposition of attitude in the study suggests that three factors i.e., equal status, cooperativeness, and identification influence an individual's attitude to sharing knowledge in a multitribal context. This implies that academic managers should consider the use of these factors to create a positive attitude for knowledge sharing in a multitribal setting. As discussed in the previous section, tribalism has taken a toll on most social activities in Ghana. The results indicate that intergroup contact theory and its associate factors i.e. equal status, cooperativeness, and institutional support could reduce an individual's sentiment (tribalism), influencing their attitude to share knowledge to people from other tribes. This suggests that management could use the premise of intergroup contact theory to reduce tribalism at the workplace. Furthermore, this study shows that an individual's intention to share knowledge is readily influenced by people who are important to him/her. Decomposing subjective norm shows that top management and immediate superiors influence the intention of individuals to share knowledge with people from other tribes. Thus, the institutions should consider the involvement of these referent groups (immediate superior and top management) in building a knowledge sharing culture as they have a direct or indirect influence on the employees' intention to share knowledge with people from other tribes.

\section{Conclusion}

The main objective of the study was to find the factors that influence an individual's intention to share knowledge in a multitribal context. Relating to existing literature, this study found that studies examining knowledge sharing in multi-tribal settings are lacking. The study utilized the Theory of Reasoned Action, Intergroup Contact Theory, and Social Identity Theory as the theoretical frameworks, which explain the relationship between the 
independent, and dependent variables of this research. Based on the relationships between the variables, hypotheses were developed. To explore these hypotheses, the quantitative method using the survey approach (questionnaire) was used to source for data from ten polytechnic institutions in Ghana. The PLS-SEM and SPSS were used as the statistical techniques to analyze the data. PLS-SEM was used to test the main hypothesized relationships stated in this study.

The results indicated that the relationships between equal status, cooperativeness and identification and attitude to share knowledge with people from other tribes were significant. However, the relationship between a common goal, institutional support and friendliness and attitude to share knowledge to people from other tribes were not supported. In addition, the study found that top management and immediately superior have influence on subjective norm to share knowledge. Attitude and subjective norm were found to have a positive significant influence on individuals' intention to share knowledge with people from other tribes. Based on these findings, the contributions of this study to academic research and practice were discussed. Akin to other research endeavours, this current study suffered certain limitations, which were presented. Practical opportunities and directions for future research were also discussed. As discussed previously, although further research has to be conducted to affirm the postulations of this study, the overall findings of this study indicate that the research models predict the individual's intention to share knowledge to people from other tribes.

\section{Limitation of the study}

As everything has its flaws, so does this current study. The study focuses only on lecturers in public tertiary institutions as respondents. These lecturers might have demonstrated a different behaviour towards knowledge sharing due to the lack of supervisors and other restrictions as compared to the lecturers in the private tertiary institutions. Hence, the urge to participate in knowledge sharing by the public institution lecturers might differ from lecturers in the private tertiary institutions. Therefore, future researchers can replicate this same study among lecturers from private institutions. In addition, another limitation is the unequal composition of tribes among the study respondents. The results show that the Akan tribe forms the majority of the tribe composition. This reflects the larger number of Akans in the Ghanaian population. Thus, this could influence the results of the study since every tribe has its own unique culture. However, the limitations of this study could also serve as a suggestion for further research.

\section{Author Statement}

The authors declare that they have no conflict of interest.

\section{ORCIID}

Eugene Okyere-Kwakye (iD) https://orcid.org/0000-0003-0143-3222

Khalil Md Nor (iD https://orcid.org/0000-0002-4622-0434 


\section{References}

Abdul Manaf, H., \& Marzuki, N. A. (2013). The roles of personality in the context of knowledge sharing: A Malaysian perspective. Asian Social Science, 10(1), 138-150.

Adeyelure, T. S., Kalema, B. M., \& Motlanthe, B. L. (2019). An empirical study of knowledge sharing: A case of South African healthcare system. Knowledge Management \& E-Learning, 11(1), 114-128.

Ajzen, I. (1991). The theory of planned behaviour. Organizational Behavior and Human Decision Processes, 50(2), 179-211.

Ajzen, I., \& Fishbein, M. (1980). Understanding attitudes and predicting social behaviour. Englewood Cliffs, NJ: Prentice-Hall.

Alkhaldi, A. N., Yusof, Z. M., \& Aziz, M. J. A. (2011). Measuring national culture impact (NCI) at an individual level: A conceptual model for capturing the NCI on knowledge sharing via video-conferencing. Journal of Knowledge Management Practice, 12(4): 9.

Allport, G. W. (1954). The nature of prejudice. Reading, MA: Addison-Wesley.

Amin, A., Hassan, M. F., Ariffin, M. B. M., \& Rehman, M. (2012). Knowledge sharing: Two-dimensional motivation perspective and the role of demographic variables. Journal of Information \& Knowledge Management, 10(2), 135-149.

Ardichvili, A., Maurer, M., Li, W., Wentling, T., \& Stuedemann, R. (2006). Cultural influences on knowledge sharing through online communities of practice. Journal of Knowledge Management, 10(1), 94-107.

Argote, L., Ingram, P., Levine, J. M., \& Moreland, R. L. (2000). Knowledge transfer in organizations: Learning from the experience of others. Organizational Behavior and Human Decision Processes, 82(1),1-8.

Aziri, B., Veseli, N., \& Ibraimi, S. (2013). Human resources and knowledge management. Paper presented at the Management, Knowledge and Learning International Conference. Zadar, Croatia.

Bartol, K. M., \& Srivastava, A. (2002). Encouraging knowledge sharing: The role of organizational rewards. Journal of Leadership \& Organization Studies, 9(1), 64-76.

Becerra-Fernandez, I., Gonzalez, A., \& Sabherwal, R. (2004). Knowledge management: Challenges, solutions and technologies. New Jersey, NJ: Pearson Education Inc.

Boateng, H., Dzandu, M. D., \& Agyemang, F. G. (2015). The effects of demographic variables on knowledge sharing. Library Review, 64(3), 216-228.

Bock, G. W., \& Kim, Y. G. (2002). Breaking the myths of rewards: An exploratory study of attitudes about knowledge sharing. Information Resources Management Journal, 15(2), 14-21.

Bock, G. W., Zmud, R. W., Kim, Y. G., \& Lee, J. N. (2005). Behavioral intention formation in knowledge sharing: Examining the roles of extrinsic motivators, socialpsychological forces and organizational climate. MIS Quarterly, 29(1), 87-111.

Bodenhausen, G. V. (2009). Diversity in the person, diversity in the group: Challenges of identity complexity for social perception and social interaction. European Journal of Social Psychology, 40(1), 1-16.

Bogenrieder, I., \& Nooteboom, B. (2004). Learning groups: What types are there? A theoretical analysis and an empirical study in a consultancy firm. Organization Studies, 25(2), 287-313.

Boh, W. F., Nguyen, T. T., \& Xu, Y. (2013), Knowledge transfer across dissimilar cultures. Journal of Knowledge Management, 17(1), 29-46.

Brown, R. (2005). Prejudice: Its social psychology. Oxford, UK: Blackwell.

Brown, J. S., \& Duguid, P. (2000). Balancing act: Capturing knowledge without killing it. Harvard Business Review, 78(3), 73-80.

Cabrera, A., \& Cabrera, E. F. (2002). Knowledge sharing dilemmas. Organization 
Studies, 23(5), 687-710.

Cabrera, A., Collins, W. C., \& Salgado, J. F. (2006). Determinants of individual engagement in knowledge sharing. International Journal of Human Resource Management, 17(2), 245-264.

Chin, W. W., Gopal, A., \& Salisbury, W. D. (1997). Advancing the theory of adaptive structuration: The development of a scale to measure faithfulness of appropriation. Information Systems Research, 8(4), 342-367.

Chiu, C. M., Hsu, M. H., \& Wang, E. T. G. (2006). Understanding knowledge sharing in virtual communities: An integration of social capital and social cognitive Theories. Decision Support Systems, 42(3), 1872-1888.

Cox, T. (2001), Creating the multicultural organization: A strategy for capturing the power of diversity. San Francisco, CA: Jossey-Bass.

Davis, F. D. (1989). Perceived usefulness, perceived ease of use, and user acceptance of information technology. MIS Quarterly. 13(3), 319-340.

Dovidio, J. F., Kawakami, K., \& Beach, K. R. (2001). Implicit and explicit attitudes: Examination of the relationship between measures of intergroup bias. In R. Brown \& S. L. Gaertner (Eds.), Blackwell Handbook of Social Psychology: Intergroup Processes (pp. 175-197). Oxford, UK: Blackwell.

Feuchte, F. (2010). Can we make a difference tomorrow? A systematic evaluation of peace education programme implemented with liberian refugees. Doctoral dissertation, Friedrich Schiller University Jena, Germany.

Fulk, J., Schmitz, J. A., \& Steinfield, C. W. (1990). A social influence model of technology use. In J. Fulk \& C. Steinfield (Eds.), Organizations and communication technology (pp. 117-142). Newbury Park, CA: Sage.

Fornell, C. G., \& Larcker, D. F. (1981). Evaluating structural equation models with unobservable variables and measurement error. Journal of Marketing Research, 18(1), 39-50.

Endres, M. L., Endres, S. P., Chowdhury, S. K., \& Alam. I. (2007). Tacit knowledge sharing, self-efficacy theory and application to the open community. Journal of Knowledge Management, 11(3), 92-100.

Goldberg, L. R., Johnson, J. A., Eber, H. W., Hogan, R., Ashton, M. C., Cloninger, C. R., \& Gough, H. C. (2006). The international personality item pool and the future of public-domain personality measures. Journal of Research in Personality, 40(1), 8496.

Gumus, M. (2007). The effect of communication on knowledge sharing in organizations. Journal of Knowledge Management Practice, 8(2): 2.

Gupta, A. K., \& Govindarajan, V. (2000). Knowledge management's social dimension: Lessons from Nucor Steel. Sloan Management Review, 42(1), 71-80.

Hair, J. F., Hult, G. T. M., Ringle, C. M., \& Sarstedt, M. (2014). A primier on partial least squares structural equation modeling (PLS-SEM). Thousand Oaks, CA: Sage.

Hall, H. (2001). Input-friendliness: Motivating knowledge sharing across intranets. Journal of Information Science, 27(3), 139-146.

Hamphill, D., \& Leskowitz, S. (2012). DIY activists: Communities of practice, cultural dialogism, and radical knowledge sharing. Adult Education Quarterly, 63(1), 57-77.

Hassandoust, F., Logeswaran, R., \& Kazerouni, M. F. (2011). Behavioral factors influencing virtual knowledge sharing: Theory of reasoned action. Journal of Applied Research in Higher Education, 3(2), 116-134.

Hau, Y. S., Kim, B., Lee, H., \& Kim, Y. G. (2013). The effects of individual motivations and social capital on employees' tacit and explicit knowledge sharing intentions. International Journal of Information Management, 33(2), 356-366.

Hew, K. F., \& Hara, N. (2007). Knowledge sharing in online environments: A quantitative case study. Journal of the American Society for Information Science and 
Technology, 58(14), 2310-2324.

Hislop, D. (2003). Linking human management and knowledge management via commitment: A review and research agenda. Employee Relations, 25(2), 182-202.

Ho, L. A., Kuo, T.-H., \& Lin, B. (2012). How social identification and trust influence organizational online knowledge sharing. Internet Research, 22(1), 4-28.

Holmstrom, J. (2014). File sharing beyond grabbing and running exploring the sense of community in a peer-to-peer file sharing network. Convergence, 21(4), 437-449.

Huang, Q., Davison, R. M., \& Gu, J. (2008). Impact of personal and cultural factor on knowledge sharing in China. Asia Pacific Journal Management, 25, 431-471.

Hwang, Y., \& Kim, J. D. (2007). Understanding affective commitment, collectivist culture, and social influence in relation to knowledge sharing in technology mediated learning. IEEE Transaction on Professional Communication, 50(3), 232-248.

Ibragimova, B., Ryan, S. D., Windsor,J. C., \& Prybutok, V. R. (2012). Understanding the antecedents of knowledge sharing: An organizational justice perspective. Informing Science: The International Journal of an Emerging Transdiscipline, 15, 183-206.

Igbaria, M., Parasuraman, S., \& Baroudi, J. J. (1996). A motivational model of microcomputer usage. Journal of Management Information Systems 13(1), 127-143.

Ipe, M. (2003). Knowledge sharing in organisations: A conceptual framework. Human Resource Development Review, 2(4), 337-359.

Jarvenpaa, S. L., \& Staples, D. S. (2001). Exploring perceptions of organizational ownership of information and expertise. Journal of Management Information Systems, $18(1), 151-184$.

Jolaee, A., Nor, M. K., Khani, N., \& Yusuf, M. N. (2014). Factors affecting knowledge sharing intention among academic staff. International Journal of Educational Management, 28(4), 413-431.

Kankanhalli, A., Tan, B. C. Y., \& Wei, K. K. (2005). Contributing knowledge to electronic knowledge repositories: An empirical investigation. MIS Quarterly. 29(1), 113-143.

Karahanna, E., Evaristo, J. R., \& Srite, M. (2005). Levels of culture and individual behavior: An integrative perspective. Journal of Global Information Management, 13(2), 1-20

Keong, Y. C., \& Subhi, S. N. (2015). The role of knowledge sharing in the learning process, among Iraqi EL postgraduate students in UKM. International Journal of Education and Research, 3(12), 185-195.

Khatri, N., Tsang, E. W. K., \& Begley, T. M. (2006). Cronyism: A cross-cultural analysis. Journal of International Business Studies, 37(1), 61-75.

Kim, J., Lee, C., \& Elias, T. (2015). Factors affecting information sharing in social networking sites amongst university students. Online Information Review, 39(3), 290309.

Kim, S., \& Lee, H. (2005). Employee knowledge sharing capabilities in public and private organizations: Does organizational context matter? In Proceedings of the 38th Hawaii International Conference on System Sciences. USA.

KPMG. (2003). Insights from KPMG's European knowledge management survey 2002/2003. KPMG Consulting.

Krahe, B., \& Altwasser, C. (2006). Changing negative attitudes towards persons with physical disabilities: An experimental intervention. Journal of Community \& Applied Social Psychology, 16, 59-69.

Lau, D. C., \& Murnighan, J. K. (1988). Demographic diversity and faultlines: The compositional dynamics of organizational groups. The Academy of Management Review, 23(2), 325-340.

Lee, C. K., \& Al-Hawarden, S. (2002). Factors impacting knowledge sharing. Journal of 
Information and Knowledge Management, 1(1), 49-56.

Lee, H., Reid, E., \& Kim, W. G. (2014). Understanding knowledge sharing in online travel communities: Antecedents and the moderating effects of interaction model. Journal of Hospitality and Tourism Research, 38(2), 222-242.

Lee, J. N. (2001). The impact of knowledge sharing, organizational capability and partnership quality on IS outsourcing success. Information \& Management, 38(5), 323-335.

Li, J., Liu, M., \& Liu, X. (2016). Why do employees resist knowledge management systems? An empirical study from the status quo bias and inertia perspectives. Computers in Human Behavior, 65, 189-200.

Libowitz, J., \& Chen, Y. (2001). Developing knowledge-sharing proficiencies: Building a supportive culture for knowledge sharing. Knowledge Management Review, 3(6), 12 15.

Lin, H. F. (2006). Impact of organizational support on organizational intention to facilitate knowledge sharing. Knowledge Management Research \& Practice, 4(1), 26-35.

Lin, H. F. (2007). Knowledge sharing and firm innovation capability: An empirical study. International Journal of Manpower, 28(3/4), 315-332.

Liu, C. C. (2008). The relationship between Machiavellianism and knowledge sharing willingness. Journal of Business and Psychology, 22(3), 233-240.

Mahmood, A., Qureshi, M. A., \& Shahbaz, Q., (2011). An examination of the quality of tacit knowledge sharing through the theory of reasoned action. Journal of Quality and Technology Management, 7(1), 39-55.

Mehrabani, S. E., \& Mohamad, N. A. (2011). Brief review of succession planning and management approach. Paper presented at the 3rd International Conference on Advanced Management Science. Kuala Lumpur, Malaysia.

Murphy, P. J., Cooke, R, A., \& Lopez, A. (2013). Firm culture and performance: Intensity's effects and limits. Management Decision, 51(3), 661-679.

Nahapiet, J., \& Ghoshal, S. (1998). Social capital, intellectual capital, and the organizational advantage. Academy of Management Review, 23(2), 242-266.

Nesheim, T., \& Smith, J. (2015), Knowledge sharing in projects: Does employment arrangement matter? Personnel Review, 44(2), 255-269.

Nguyen, T. M., Dinh, T. V., \& Tuan, N. P. (2019). Online knowledge sharing in Vietnamese tele-communication companies: An integration of social psychology models. Knowledge Management \& E-Learning, 11(4), 497-521.

Nonaka, I., \& Tekeuchi, H. (1995). The knowledge creating company: How Japanese companies create the dynamics of innovation. London, UK: Oxford University Press.

Noor, N. M., \& Salim, J. (2011). Factors influencing employee knowledge sharing capabilities in electronic government agencies in Malaysia. International Journal of Computer Science, 8(4), 106-114.

Okyere-Kwakye, E., Nor, K. M., Soehod, K., \& Zaitul. (2019). Intergroup contact theory: Examining knowledge sharing among individuals from different tribes. International Journal of Knowledge Management (IJKM), 15(2), 81-96.

Rafique, M., Hameed, S., \& Agha, M. H. (2017). Impact of knowledge sharing, learning adaptability and organizational commitment on absorptive capacity in pharmaceutical firms based in Pakistan. Journal of Knowledge Management, 22(1), 44-56.

Rahman, M. S., Khan, A. H., Alam, M. M., Mustamil, N., \& Chong, C. W. (2014). A comparative study of knowledge sharing pattern among the undergraduate and postgraduate students of private universities in Bangladesh. Library Review, 6(8/9), 653-669.

Riege, A. (2005). Three-dozen knowledge sharing barriers that managers must consider. Journal of Knowledge Management, 9(3), 18-25. 
Ringle, C. W., Wende, S., \& Will, A. (2005). Smartpls 2.0. University of Hamburg, Germany.

Rosendaal, B. (2009). Sharing knowledge, being different and working as a team. Knowledge Management Research \& Practice, 7(1), 4-14.

Ryu, S., Ho, S. H., \& Han, I. (2003). Knowledge sharing behavior of physicians in hospitals. Expert Systems with Applications, 25(1), 113-122.

Panahi, S., Watson, J., \& Partridge, H. (2013). Towards tacit knowledge sharing over social web tools. Journal of Knowledg Management, 17(3), 379-397

Pettigrew, A. M. (1973). The politics of organizational decision making. London, UK: Tavistok.

Probst, G., Raub, S., \& Romhardt, K. (2000). Managing knowledge-building blocks for success. West Sussex, UK: John Wiley and Sons, Ltd.

Punniyamoorthy, M., \& Asumptha, J. A. (2019). A study on knowledge sharing behavior among academicians in India. Knowledge Management \& E-Learning, 11(1), 95-113.

Rehab, R., \& Wahyni, P. (2013). Predicting knowledge sharing intention based on theory of reasoned action framework: An empirical study on higher education institution. American International Journal of Contemporary Research, 3(1), 138-147.

Slump, A. (2013). Knowledge sharing behavior of dominant and subordinated ethnicities in a work environment - A qualitative study to the underlying mechanism. Master's thesis, Tilburg University, Netherlands.

Spears, R., Doosje, B., \& Ellemers, N. (1997). Ingroup stereotyping in the face of threats to group status and distinctiveness: The role of group identification. Personality and Social Psychology Bulletin, 23(5), 538-553.

Srivastava, A., Bartol, K. M., \& Locke, E. A. (2006). Empowering leadership in management teams: Effects on knowledge sharing, efficacy, and performance. Academy of Management Journal, 49(6), 1239-1251.

Tajfel, H., \& Turner, J. (1979). An integrative theory of intergroup conflict. In W. G. Austin \& S. Worchel (Eds.), The social psychology of intergroup relations (pp. 3347). Monterey, CA: Brooks/Cole.

Tan, H. H., \& Zhao, B. (2003). Individual- and perceived contextual-level antecedents of individual technical information inquiry in organizations. The Journal of Psychology, 137(6), 597-621.

Taylor, S., \& Todd, P. A. (1995). Understanding information technology usage: A test of competing models. Information Systems Research, 6(2), 144-176.

Teece, D. J. (2003). Expert talent and the design of (professional services) firms. Industrial and Corporate Change, 12(4), 895-916.

Tohidinia, Z., \& Mosakhani, M. (2010). Knowledge sharing behavior and its predictors. Industrial Management \& Data Systems, 110(4), 611-631.

Tsai, M.-T., \& Cheng, N.-C. (2012). Understanding knowledge sharing between IT professionals - An integration of social cognitive and social exchange theory. Behaviour \& Information Technology, 31(11), 1069-1080.

Tsui, L., Chapman, S. A., \& Stewart, S. (2006). A handbook on knowledge sharing: Strategies and recommendations for researchers, policymakers, and service providers. Edmonton, Canada: Community University-Partnership for the Study of Children, Youth and Families.

Van den Hooff, B., \& de Ridder, J. A., (2004). Knowledge sharing in context: The influence of organizational commitment, communication climate and CMC use on knowledge sharing. Journal of Knowledge Management, 8(6),117-130.

Venkatesh, V., \& Brown, S. A. (2001). A longitudinal investigation of personal computers in homes: Adoption determinants and emerging challenges. MIS Quarterly, 25, 71-102. 
Wasko, M. M., \& Faraj, S. (2005). Why should I share? Examining social capital and knowledge contribution in electronic networks of practice. MIS Quarterly, 29(1), 3557.

Wilmot, W. W., \& Hocker, J. L. (2001). Interpersonal conflict (6th ed.). Boston, MA: McGraw-Hill.

Yahya, S., \& Goh, W. (2002), Managing human resources toward achieving knowledge management. Journal of Knowledge Management, 6(5), 457-468.

Yilmaz, C., \& Hunt, S. D. (2001). Salesperson cooperation: The influence of relational, task, organizational, and personal factors. Journal of the Academy of Marketing Science, 29(4), 335-357.

Zhang, X., Liu, S., Deng, Z., \& Chen, X (2017). Knowledge sharing motivations in online health communities: A comparative study of health professionals and normal users. Computers in Human Behavior, 75, 797-810. 


\section{Appendix I}

\section{Questionnaire Items}

\begin{tabular}{llclc}
\hline No. & Constructs & Items & Original Scales & Reliability \\
\hline 1 & Intention to share knowledge & 5 & Ryu et al. (2003) & 0.93 \\
2 & Attitude to share knowledge & 5 & Bock et al. (2005) & 0.89 \\
3 & Subjective norm to share knowledge & 4 & Ryu et al. (2003) & 0.86 \\
4 & Top management & 4 & Lin (2007) & 0.72 \\
5 & Immediate superior & 5 & Taylor and Todd (1995) & 0.82 \\
6 & Identification & 4 & Chiu et al. (2006) & 0.89 \\
7 & Cooperativeness & 4 & Yilmaz and Hunt (2001) & 0.80 \\
8 & Common goal & 4 & Chiu et al. (2006) & 0.70 \\
9 & Friendliness & 5 & Goldberg et al. (2006) (IPIP) & 0.81 \\
10 & Equal status & 5 & Spears et al. (1997) & 0.77 \\
11 & Institutional support & 4 & Jolaee et al. (2014) & 0.88 \\
\hline
\end{tabular}

\begin{tabular}{|c|c|}
\hline No. & Statement \\
\hline & Equal Status \\
\hline 1 & I consider myself to have equal social status with my co-workers. \\
\hline 2 & $\begin{array}{l}\text { I do not see any major difference between myself and other co-workers in } \\
\text { terms of social status. }\end{array}$ \\
\hline 3 & I perceived myself to be of equal social status as my co-workers. \\
\hline 4 & My co-workers and I are of equal social status. \\
\hline \multirow[t]{2}{*}{5} & I and my co-workers have equal social status. \\
\hline & Cooperativeness \\
\hline 6 & I find it necessary to help my co-workers when they are in need. \\
\hline 7 & I work on-behalf of my co-workers when they are not available. \\
\hline 8 & I find it very satisfied in helping other co-workers. \\
\hline \multirow[t]{2}{*}{9} & I feel honoured when my co-workers ask for my help. \\
\hline & Common goal \\
\hline 10 & I agree with the mission and vision of the organization. \\
\hline 11 & I share with what my organization consider as important. \\
\hline 12 & I agree with my organizational goals. \\
\hline \multirow[t]{2}{*}{13} & I share the vision and mission of my organization. \\
\hline & Institutional Support \\
\hline 14 & $\begin{array}{l}\text { My organization has appropriate technology in place (e.g. academic portal, } \\
\text { web site, e-mail) to share knowledge to co-workers from other tribes. }\end{array}$ \\
\hline 15 & $\begin{array}{l}\text { My organization supports forming informal networks (e.g. community of } \\
\text { practice) that promote knowledge sharing to co-workers from other tribes. }\end{array}$ \\
\hline 16 & $\begin{array}{l}\text { My organization has process in place (e.g. meeting, colloquium, } \\
\text { intellectual discourse session, etc.) for knowledge sharing to co-workers }\end{array}$ \\
\hline
\end{tabular}


from other tribes.

My organization encourages me to share new knowledge with my coworkers from other tribes.

\section{Friendliness}

I make friends easily with my co-workers at work.

I feel comfortable around my co-workers at work.

I cheer up my co-workers at work.

I warm quickly to my co-workers at work.

I act comfortably with my co-workers at work.

\section{Identification}

I am proud to be part of this organization.

I have the feeling of togetherness or closeness with my organizational members.

I have a strong positive feeling towards my organization.

I feel a sense of belonging towards my organization.

\section{Immediate Superior}

My immediate superior thinks that, I should share knowledge with my coworkers from other tribes.

I share my knowledge with my co-workers from other tribes because my immediate superiors share their knowledge with co-workers from other tribes.

I would have to share knowledge with my co-workers from other tribes if my immediate superiors have already shared their knowledge with coworkers from other tribes.

I have to share knowledge with my co-workers from other tribes because my immediate superiors think I should share with them.

My immediate superior, who influences my behavior would think that I should share knowledge to people from other tribes.

\section{Top Management}

My top management think that, I should share knowledge with my coworkers from other tribes.

I share my knowledge with my co-workers from other tribes because my top management share their knowledge with co-workers from other tribes. I would have to share knowledge with my co-workers from other tribes if my top management have already shared their knowledge with co-workers from other tribes.

I have to share knowledge with my co-workers from other tribes because my top management encourages us to share knowledge with co-workers from other tribes.

\section{Attitude towards intention to share knowledge}

To me, sharing knowledge with my co-workers from other tribes is beneficial.

To me, sharing knowledge with my co-workers from other tribes is good.

To me, sharing knowledge with my co-workers from other tribes is a good idea. 
To me, sharing knowledge with my co-workers from other tribes is valuable.

40 To me, sharing knowledge with my co-workers from other tribes is a wise decision.

\section{Subjective Norm}

41 People who are important to me, think I should share knowledge with my co-workers from other tribes.

People who influence my behaviour, think I should share knowledge with my co-workers from other tribes.

People whose opinion I value, think I should share knowledge with my coworkers from other tribes.

44 People whose opinion I value would approve of my behaviour to share knowledge with people from other tribes.

\section{Intentions to share knowledge}

I intend to share knowledge with my co-workers from other tribes in the future.

I will always make an effort to share knowledge with my co-workers from other tribes in the future.

47 I will try to share my expertise with my co-workers from other tribes in the future.

48 I plan to share my experience with my co-workers from other tribes in the future. tribes in the future. 